\title{
A NEW GENUS OF ANT-MIMICKING SPIDER WASPS FROM AUSTRALIA (HYMENOPTERA, POMPILIDAE)*
}

\author{
By Howard E. Evans \\ Museum of Comparative Zoology
}

Australia has a rich fauna of spider wasps (Pompilidae), but aside from numerous species descriptions by R. E. Turner, Frederick Smith, and others, it is almost totally unstudied. There would be little excuse for further species descriptions if it were not for two factors: (I) one of these species was figured in the recent book The Insects of Australia, where it was identified as simply "brachypterous Pepsini," although it is such an unusual wasp that one is immediately curious as to its proper position in the classification; and (2) these are among the most striking ant mimics known, and furthermore each of the two known species appears to mimic one particular species of ant.

Ant mimicry is not wholly unknown in the Pompilidae. I regard some of the pale-bodied, banded-winged North American Ageniella as generalized ant mimics (e.g. A conflicta Banks). Here the wing pattern creates the appearance of a wingless insect with several body constrictions, such as an ant. It is probable that some of the apterous and brachypterous Ctenoceratini of Africa are ant mimics, although Arnold (1932) suggests that some may mimic mutillids.

In the present instance there seems little question that ant mimicry is involved, and it is possible to name the model in each case. The one figured in The Insects of Australia, here described as Iridomimus spilotus, is mounted on a card point on the same pin as a worker Iridomyrmex rubriceps Forel. ${ }^{1}$ Although I know nothing of the circumstances under which this was collected, the striking resemblance of the pompilid and the ant suggests that whoever collected them took them in close proximity and was impressed by this resemblance.

*Published with the aid of a grant from the Museum of Comparative Zoology at Harvard College.

${ }^{1}$ Ant determinations are by Dr. R. W. Taylor, Division of Entomology, C. S. I. R. O., Canberra, Australia. Dr. Taylor found that this specimen compared favorably with a syntype of what has been called Iridomyrmex gracilis var. rubriceps Forel, but he thinks it probable that rubriceps should be regarded as a full species, perhaps not closely related to gracilis.

Manuscript received by the editor November 13, 1970. 
They are similar in size and both are yellowish with a darker metasoma; in both there is a metallic sheen to the anterior part of the body, but the pompilid differs in having a black spot on the vertex and one on the pronotum. The pompilid has very long, slender, smooth legs; there is a constriction in the middle of the mesosoma exactly paralleling that in the Iridomyrmex worker; and the wings are so small as to escape immediate notice. The resemblance between the two is indeed striking.

The second species (like the preceding known from one specimen) was collected by myself in a sandy blow-out in South Australia. This was an area in which a somewhat larger species of Iridomyrmex, viridiaeneus Viehmeyer, ${ }^{2}$ was abundant, and these ants were conspicuous because of their metallic bluish bodies. When I first observed the pompilid (described below as Iridomimus violaceus) I had no suspicion that it was not simply another worker ant of this species. Something about its gait warned me that it was not, and close inspection showed that it had minute, stalked wings and that it lacked a nodose petiole. In size, color, and general form of the mesosoma it was an almost perfect copy of a worker Iridomyrmex viridiaeneus.

Why should female pompilids with a well-developed and presumably painful sting mimic ants? Iridomyrmex purpureus and certain other species of this genus are known to produce methylheptenone and iridodial from anal glands; it is believed that the former serves as a defensive secretion while the latter may be an adherent, retarding the loss of more volatile components when discharged on a predator (Pavan and Trave, 1958; Cavill and Robertson, 1965). Thus these relatively abundant and conspicuous ants may be avoided by many or all predators. Presumably the pompilids hunt and nest in situations where one particular species of Iridomyrmex is prevalent, and it proved selectively advantageous for them to assume a common Müllerian mimetic pattern with the ant. There may, of course, have been selection for flightlessness first (we do not know what kind of spider these pompilids prey on), and if so it would be particularly advantageous for them to compensate for their inability to escape by assuming an ant-like form. It is curious that these wasps

${ }^{2}$ Dr. R. W. Taylor found my specimens to compare favorably with a syntype. This form has been considered a variety of the meat ant, Iridomyrmex purpureus Smith, but Taylor believes it is probably distinct. H.e states that it is probable that $I$. viridiaeneus and rubriceps are fairly closely related within Iridomyrmex. 


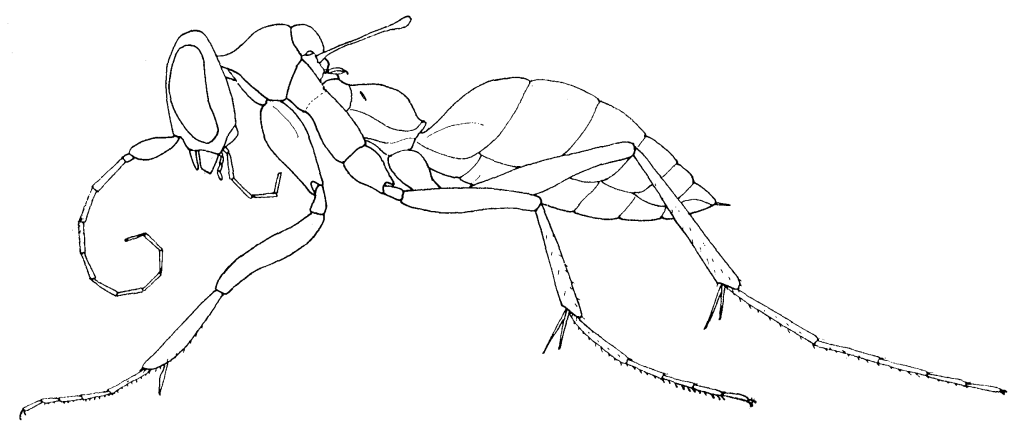

Fig. 1. Iridomimus violaceus new species, holotype (setae omitted).

appear to be so rare. I have scanned the collections of Pompilidae in all the major museums of Australia, but I have been unable to find additional specimens of these or related species.

Iridomimus, new genus

Type species: Iridomimus violaceus, new species.

Generic diagnosis (females only; males unknown). - Front wings in the form of a stalk much longer than the terminal, expanded portion, the latter with or without one or two short veins, these wings not extending beyond the base of the second metasomal tergite; hind wings minute, not surpassing the postnotum. Postnotum transversely striate, unusually long, approximately as long as the very short scutellum and metanotum combined; thoracic profile markedly constricted at the postnotum and at the mesopleura, so that the mesosoma appears to form two separate nodes both in dorsal and lateral views; mesoscutum also unusually small; pronotum large, rounded, constricted behind, with no evidence of a furrow extending laterad from the collar; mesopleura slender, the transverse furrow weak to virtually absent, located only a short distance from the top. Legs very slender and with only a few short spines, front tarsus with no evidence of a pecten, middle and hind tibiae with a few weak spines along the shaft and a few short apical spines which are somewhat splayed out; claws dentate. Second sternite of metasoma with a transverse furrow, apical tergite strongly setose but without thick bristles. Head without unusual features, clypeus transverse, truncate, antennae long and slender, base of mandibles slightly separated from bottoms of eyes; eyes convergent above, their inner margins not at all emarginate; ocelli well developed. 
Generic relationships. - The head and metasoma bear a close resemblance to those of members of the genus Priocnemis, and I would regard this genus as a derivative of a Priocnemis-like stock which has undergone many modifications of the thorax as a result of loss of flight and the evolution of ant-mimicry. Although the few spines at the apices of the tibiae are somewhat splayed out (as in Pompilinae), this condition is approached by several other genera of Pepsinae, and I would not hesitate to assign this genus to that subfamily and to the tribe Cryptocheilini, which is very well represented in Australia.

Iridomimus violaceus, new species

Holotype. - 9 , south australia: Port Germein, 28 October 1969 (H. E. Evans) [to be deposited in the Australian National Insect Collections, CSIRO, Canberra].

Description. - Length $7.5 \mathrm{~mm}$; fore wing $1.5 \mathrm{~mm}$. Body and basal parts of legs black, with strong reflections of violet and (especially on the metasoma) dark blue-green; tarsi and antennal flagellum brownish. Head, thorax, and propodeum with sparse, fairly long setae; coxae and to a lesser extent the femora with pale setae. Clypeus $3 \times$ as wide as high; first four antennal segments in a ratio of about 23:9:30:27, segment three $4.6 \times$ as long as its apical width; middle interocular distance $.53 \times$ transfacial distance; upper interocular distance $.64 \times$ lower interocular distance; postocellar and ocello-ocular distances subequal; temples, in lateral view, not nearly as wide as eye. Pronotum smoothly rounded; mesoscutum strongly humped; propodeum smoothly rounded; fore wings reaching to about the middle of the propodeum, spatulate, evidently supported by a single vein; hind wings scale-like, about $3 \times$ as long as wide. Apical tarsal segments without spines beneath, but other tarsal segments with short spines in several rows beneath; tibiae smooth, with scattered short spines. (See Fig. I).

Iridomimus spilotus, new species

Holotype. - + , NORThern territory: Powell Creek, June, I947 (no collector given; on a card point, an additional card point bearing a worker ant, Iridomyrmex rubriceps Forel). [Australian National Insect Collections, CSIRO, Canberra].

Description. - Length $6 \mathrm{~mm}$; fore wing $2.3 \mathrm{~mm}$. Head, mesosoma, and first metasomal segment predominantly pale ferruginuous; ocellar area covered with a black spot, from which dark streaks 
pass to the eye tops; pronotum with a central black spot, this spot with a bluish sheen; both dark and light areas of the front and vertex with a violet sheen; metasoma beyond basal segment fuscous, with weak violet reflections; antennae dusky ferruginous, legs also of this color but femora rather strongly infuscated above; fore wings fuscous, the apical O.I contrastingly white. Body clothed with a delicate silvery to cinereous pubescence, but with no erect setae except for a few on the clypeus and on the front coxae. Clypeus $2.5 \times$ as wide as high; first four antennal segments in a ratio of about I 5:5:19:18, segment three $4 \times$ as long as its apical width; middle interocular distance $.58 \times$ transfacial distance; upper interocular distance .78 $\times$ lower interocular distance; ocellar triangle compact, ocello-ocular distance nearly twice the postocellar distance; temples, in lateral view, somewhat more than half as wide as the eyes. Pronotum rounded gently, not as convex as in violaceus, mesoscutum small and nearly flat, not nearly as prominent as in that species; propodeum elongate, gently arched. Fore wings reaching to base of second metasomal tergite, in the form of a long, linear stalk which slightly exceeds in length a slightly expanded apical portion in the base of which a reduced venation can be observed (including, apparently, a small stigma and short radial vein; hind wings slender, pointed, reaching to the anterior margin of the propodeum. Legs very slender, spined much as in violaceus, but the middle tibiae slightly more strongly spinose and the apical tarsal segments with one or two weak spines beneath.

Remarks. - This specimen was figured in The Insects of Australia, p. 930, fig. 37.28B. This line drawing, by T. Binder, is small but essentially correct in all details. When it was drawn the specimen was apparently complete, but it is now lacking most of the hind legs.

Arnold, G.

\section{Literature Cited}

1932. The Psammocharidae of the Ethiopian region. Part II. Ann. Transvaal Mus., 15: 41-122.

Cavill, G. W. K., and P. L. Robertson

1965. Ant venoms, attractants, and repellents. Science, 149: 1337-1345.

Commonwealth Scientific and Industrial Research Organization, DiviSION OF ENTOMOLOGY.

1970. The Insects of Australia. Melbourne: Melbourne Univ. Press, $1029 \mathrm{pp}$.

Pavan, M., and R. Trave

1958. Études sur les Formicidae. IV. Sur le venin du dolichodéride Tapinoma nigerrimum Nyl. Insectes Sociaux, 5: 299-308. 

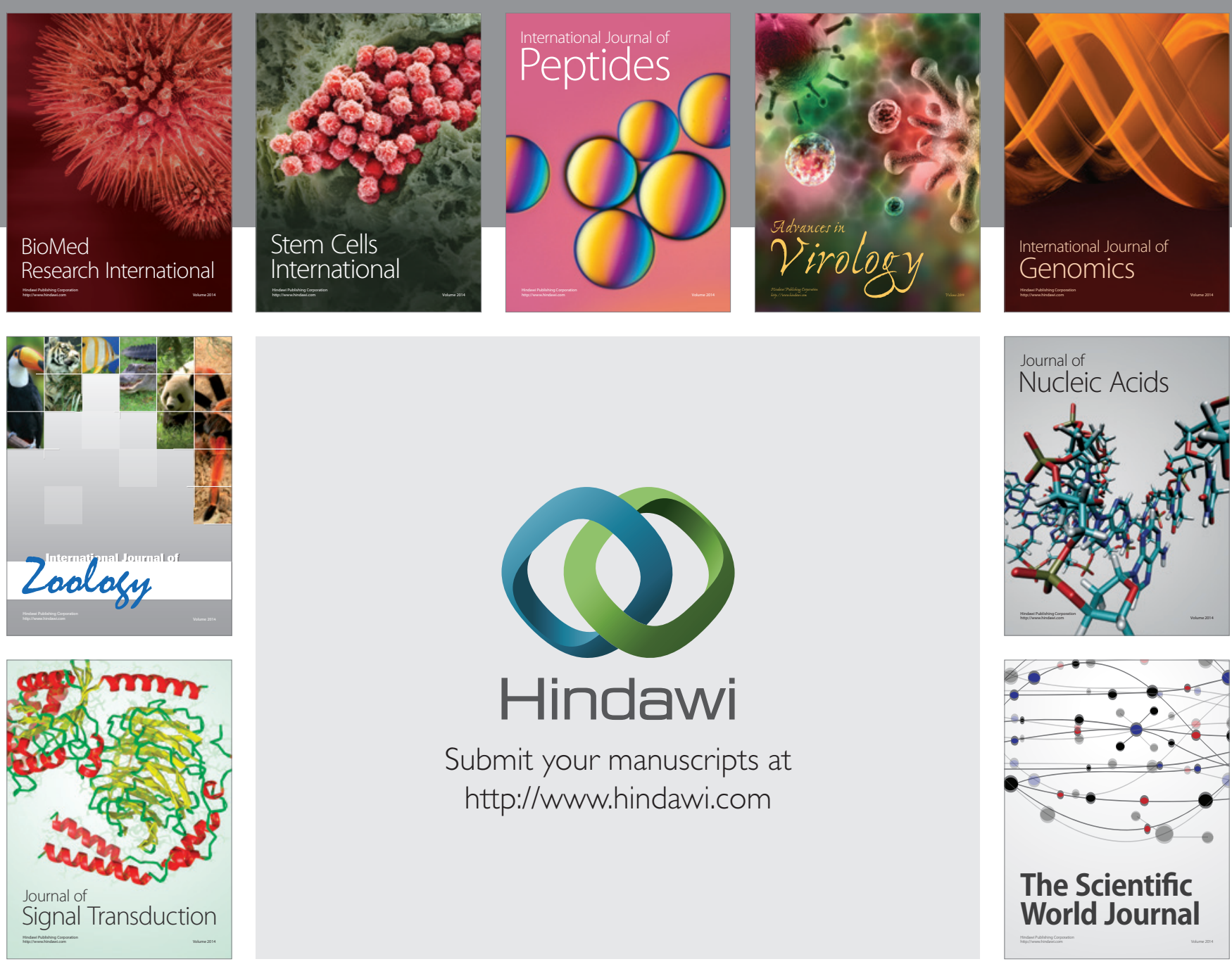

Submit your manuscripts at

http://www.hindawi.com
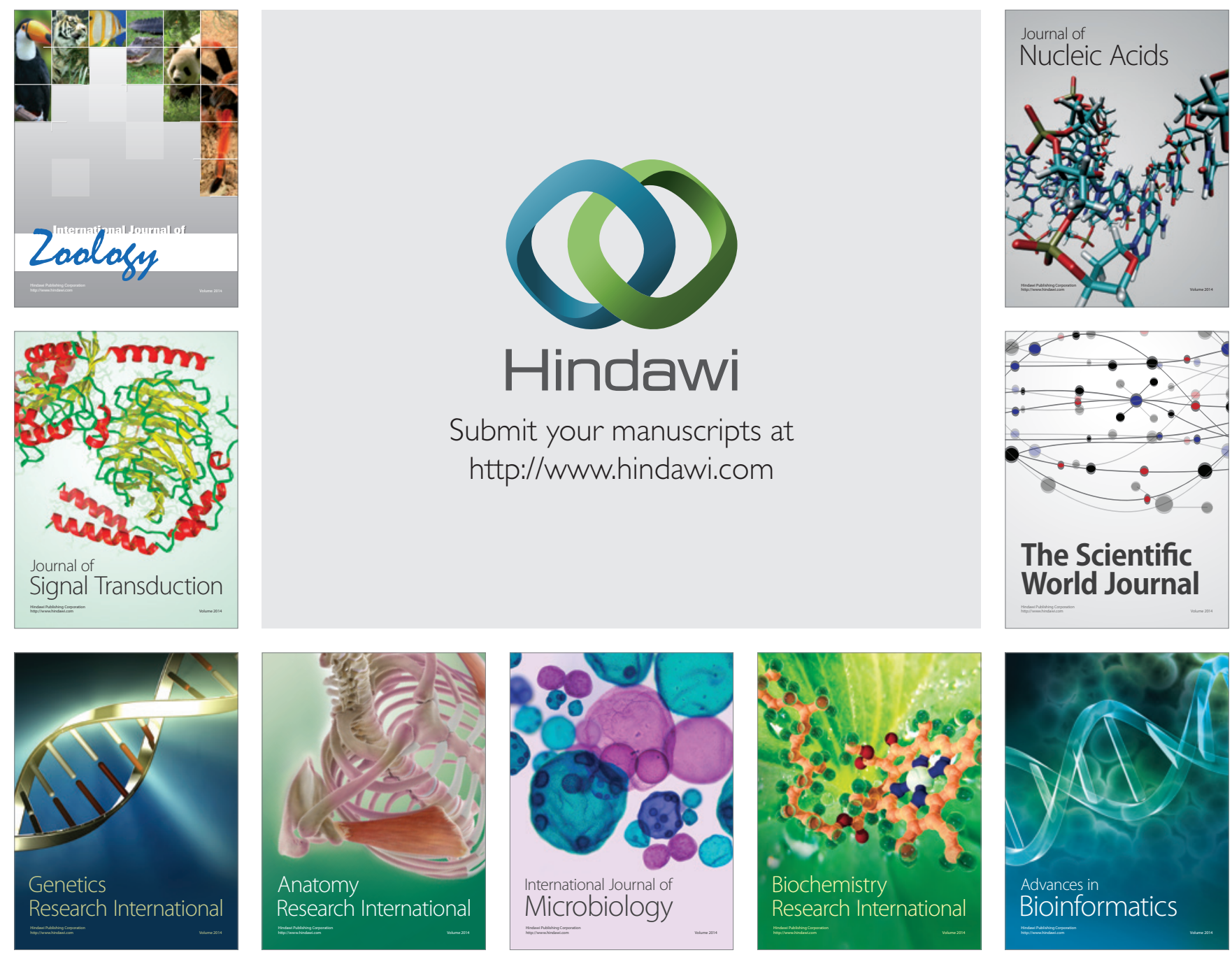

The Scientific World Journal
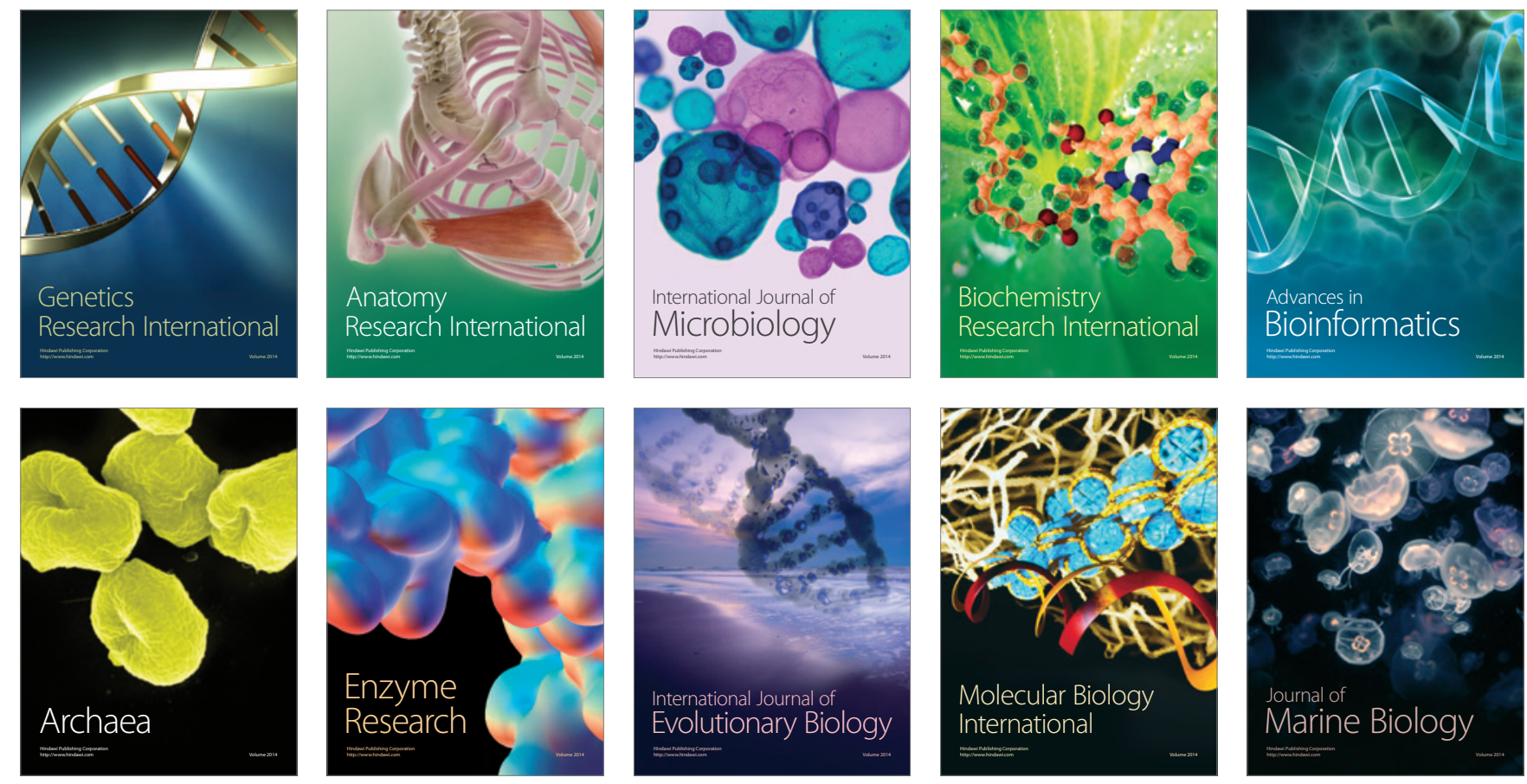